Pesq. Vet. Bras. 29(3):215-219, março 2009

\title{
Prevalência de anticorpos anti-Chlamydophila spp. em propriedades rurais com histórico de aborto bovino no estado do Paraná1
}

\author{
Francielle G. Silva-Zacarias ${ }^{2}$, Kledir A.H. Spohr², Bruna A.C. Lima², Juliana A. \\ Dias $^{2}$, Ernst E. Müller ${ }^{3}$, José S. Ferreira Neto ${ }^{4}$, Carlo Turilli ${ }^{3}$ e Julio C. Freitas ${ }^{3^{*}}$
}

\begin{abstract}
Silva-Zacarias F.G., Spohr K.A.H., Lima B.A.C., Dias J.A., Müller E.E., Ferreira Neto J.S., Turilli C. \& Freitas J.C. 2009. [Prevalence of antibodies against Chlamydophila spp. in herds with bovine abortion of Paraná state, Brazil.] Prevalência de anticorpos anti-Chlamydophila spp. em propriedades rurais com histórico de aborto bovino no estado do Paraná. Pesquisa Veterinária Brasileira 29(3):215-219. Departamento de Medicina Veterinária Preventiva, Universidade Estadual de Londrina, Rodovia Celso Garcia Cid 380, Cx. Postal 6001, Londrina, PR 86051-990, Brazil. E-mail: freitasj@uel.br

Chlamydophila abortus is a recognized cause of bovine epizootic abortion. Abortion, premature birth and weak lamb/calf, stillbirth and repeat breeding in irregular intervals are the most frequent disease manifestations. The complement fixation test is the recommended by the World Organization of Animal Health (OIE) for Chlamydophila spp. serologic diagnosis. The aim of this study was estimate the prevalence of antibodies against Chlamydophila spp. in cattle herds with abortion, selected inside the sampling design of National Program of Control and Erradication of Brucellosis in Paraná state. Serum samples of 3,102 cows (age $\geq 24$ months) from 373 herds were analyzed by complement fixation test. Totally, $44(1.42 \%)$ animal were positive with titers $\geq 32$. The seroprevalence of Chlamydophila spp. in the herds was $8.82 \%(6.15 \%-12.17 \%)$. Four variables were associated with seroprevalence for Chlamydophila spp. in the final model of logistic regression: confined or semi-confined breeding ( $\mathrm{OR}=3.339, P=0.004)$, farms with less than 35 cows $(\mathrm{OR}=3.339, P=0.017)$, abortion in the pasture $(\mathrm{OR}=2.372, P=0.037$ ) and pasture rent $(\mathrm{OR}=3.398, P=0.006)$ were risk factors for Chlamydophila spp. This bacterium infected a small number of cattle from herds with abortion in Paraná state. Chlamydophila spp impact as abortion cause is reduced in this state.
\end{abstract}

INDEX TERMS: Chlamydophila abortus, bovine epizootic abortion, serology, bacteria.

RESUMO.- Chlamydophila abortus é o agente etiológico do aborto epizoótico bovino, cujas manifestações clínicas mais freqüentes são aborto, nascimento de bezerros pre-

\footnotetext{
${ }^{1}$ Recebido em 28 de abril de 2008.

Aceito para publicação em 3 de outubro de 2008.

${ }^{2}$ Programa de Pós-Graduação em Ciência Animal, Universidade Estadual de Londrina (UEL), Londrina, Paraná.

${ }^{3}$ Departamento de Medicina Veterinária Preventiva, Centro de Ciências Agrárias, UEL, Rodovia Celso Garcia Cid 380, Cx. Postal 6001, Londrina, PR 86051-990, Brasil. *Autor para correspondência: freitasj@uel.br

${ }^{4}$ Departamento de Medicina Veterinária Preventiva e Saúde Animal, Faculdade de Medicina Veterinária e Zootecnia, Universidade de São Paulo (USP), Av. Prof. Dr. Orlando Marques de Paiva 87, Cidade Universitária, São Paulo, SP 05508-270, Brasil.
}

maturos e de animais fracos, natimorto e repetição de cio em intervalos irregulares. O objetivo deste trabalho foi estimar a prevalência de anticorpos anti-Chlamydophila spp. em fêmeas bovinas de propriedades rurais com histórico de aborto, selecionadas dentro do delineamento amostral do Plano Nacional de Controle e Erradicação da Brucelose e Tuberculose no estado do Paraná. Foram testadas pela prova de fixação de complemento 3.102 amostras de soro de fêmeas bovinas (idade $\geq 24$ meses), provenientes de 373 propriedades. Ao total, $44(1,42 \%)$ animais foram positivos com títulos $\geq 32$. A prevalência de focos foi de $8,82 \%$ $(6,15 \%-12,17 \%)$. Animais confinados ou semi-confinados (OR=3.339, $P=0.004$ ), propriedade com menos de 35 matrizes $(\mathrm{OR}=3.339, P=0.017)$, presença de produtos do aborto 
na pastagem ( $\mathrm{OR}=2.372, P=0.037$ ) e aluguel de pasto (OR=3.398, $P=0.006$ ) foram considerados fatores de risco para Chlamydophila spp. A infecção por Chlamydophila spp. acometeu um número pequeno de animais, oriundos de propriedades com histórico de aborto. A importância deste agente como causa de aborto em bovinos no estado do Paraná, se existir, é muito pequena.

TERMOS DE INDEXAÇÃO: Chlamydophila abortus, aborto epizoótico bovino, sorologia, bactéria.

\section{INTRODUÇÃO}

Bactérias da família Chlamydiaceae infectam várias espécies de mamíferos e aves domésticas e selvagens, além do homem. As manifestações clínicas causadas por estas bactérias são variadas e dependem da espécie animal e bacteriana envolvida (Schachter \& Caldwell 1980, Corsaro et al. 2003). As espécies Chlamydophila abortus ( $C$. abortus), anteriormente classificada como Chlamydia psittacisorotipo 1, e Chlamydophila pecorum (C. pecorum), anteriormente classificada como Chlamydia psittacisorotipo 2, são as mais importantes, do ponto de vista epidemiológico, para a espécie bovina (Longbottom \& Coulter 2003).

C. abortus é responsável por alterações reprodutivas denominadas aborto epizoótico bovino (Everett 2000, OIE 2004). O abortamento nas últimas duas ou três semanas de gestação normalmente é o primeiro sinal clínico da infecção por $C$. abortus, porém o nascimento de bezerros prematuros e de animais fracos, natimorto, repetição de cio em intervalos irregulares, aumento no intervalo entre partos e do número de coberturas ou de inseminações, por gestação, também são observados. Nos machos em idade reprodutiva os sinais clínicos não são observados com freqüência, entretanto podem ocorrer vesiculites, epididimites e orquites (Longbottom \& Coulter 2003).

O aborto epizoótico bovino já foi relatado em vários países, principalmente na Europa e nos EUA, com prevalências superiores a $45 \%$ em propriedades com problemas reprodutivos. (Griffiths et al. 1995, Cavirani et al. 2001, Kaltenboeck et al. 2005, Niemczuk 2005). No Brasil, o único levantamento sorológico realizado em bovinos apontou $5,3 \%$ de animais sororreatores para o gênero Chlamydophila no estado de São Paulo (Igayara-Souza et al. 2004).

A infecção por $C$. pecorum também ocorre em bovinos, ovinos, caprinos, suínos e eqüinos (Everett 2000). Apesar de relatos de abortamentos em bovinos, o quadro clínico mais expressivo é a encefalomielite esporádica, além de conjuntivite, pneumonia, encefalite, enterite e poliartrite em animais jovens. As infecções inaparentes são mais freqüentes, com a eliminação de $C$. pecorum nas fezes (Kaltenboeck et al. 2005).

Para o diagnóstico laboratorial de $C$. abortus, a prova de fixação de complemento é a técnica recomendada pela Organização Mundial de Saúde Animal (OIE 2004). Esta técnica detecta anticorpos produzidos contra 0 lipopolissacarídeo presente em todos os membros da família Chlamydiaceae, assim a reação cruzada entre $C$. abortus e C. pecorum é uma desvantagem desta técnica, porém os títulos observados nestas reações são freqüentemente inferiores a 32 (Stamp et al. 1952, Donn et al. 1997a, Twomey et al. 2006). A sensibilidade da prova de fixação de complemento é diretamente influenciada pela classe de imunoglobulina envolvida na resposta imune que o animal desenvolve frente à infecção. Em bovinos, a resposta humoral desenvolvida nas infecções por $C$. abortus são IgG1 e lgG2, mas somente a lgG1 (presente nas primeiras 3-4 semanas pós-infecção) fixa o complemento de cobaio (Schmeer et al. 1987, Twomey et al. 2006). Apesar de suas limitações, a prova de fixação de complemento tem sido utilizada em países onde existem programas de controle de aborto por $C$. abortus (Buendía et al. 2001, Longbottom \& Coulter 2003).

Nos ruminantes, os abortamentos são responsáveis por elevadas perdas econômicas na pecuária mundial. Devido sua etiologia multifatorial, a utilização de provas laboratoriais é necessária para a determinação precisa do agente envolvido (Otte et al. 1995, Hässig \& Lubsen 1998).

Considerando a escassez de informações no Brasil sobre a infecção por $C$. abortus em bovinos, o objetivo deste trabalho foi estimar a prevalência de anticorpos antiChlamydophila spp em propriedades rurais com histórico de abortamento bovino do estado do Paraná.

\section{MATERIAL E MÉTODOS}

\section{População estudada}

Foram utilizados a soroteca e o banco de dados oriundos do estudo da situação epidemiológica da brucelose bovina no estado do Paraná, realizado no âmbito do Programa Nacional de Controle e Erradicação da Brucelose e Tuberculose (Dias 2003) e planejado pelo Ministério da Agricultura (MAPA) em colaboração com a Secretaria da Agricultura e Abastecimento do estado do Paraná (SEAB-PR). Nesse estudo foram analisados 14.857 soros de matrizes com idade igual ou superior a 24 meses, provenientes de 2.098 propriedades, sorteadas dentro de sete regiões do estado. Em propriedades com até 99 fêmeas com idade igual ou superior a 24 meses foram amostradas 10 delas e naquelas com 100 ou mais foram amostradas 15 delas. O trabalho de campo foi desenvolvido de dezembro de 2001 a julho de 2002 e, além das coletas de soro, em cada propriedade que integrou o estudo também foi aplicado um questionário epidemiológico.

Dessa base, para o presente estudo foram escolhidos os soros e os questionários apenas das propriedades que relataram a ocorrência de aborto nos 12 meses anteriores à visita. Foram assim selecionadas 3.102 amostras de soro de fêmeas bovinas com idade igual ou superior a 24 meses, provenientes de 373 propriedades rurais. Embora tenha sido uma amostragem por conveniência, esta foi discretamente superior a uma amostra calculada para um nível de confiança de 95\%, uma prevalência estimada de $50 \%$ e um erro de $5,1 \%$, ou seja, 369 propriedades, segundo cálculo efetuado pelo programa Epi Info 6.0 (Dean et al. 1994).

\section{Amostras de soro}

As amostras de sangue foram coletadas por médicos veterinários e técnicos da SEAB-PR, por punção da veia jugular, 
utilizando-se agulha descartável estéril e tubo com vácuo previamente identificado. As amostras de soro obtidas foram armazenadas em microtubos de plástico e congeladas a $-20^{\circ} \mathrm{C}$.

\section{Prova de fixação de complemento}

A pesquisa de anticorpos contra Chlamydophila spp. foi realizada pela prova de fixação de complemento em microplacas (Donn et al.1997b, Lima 2007).

Como antígeno foi utilizada a estirpe $\mathrm{S} 26 / 3$ de $C$. abortus, titulado frente ao soro ovino (controle positivo) com título de 512 para C. abortus. Soro fetal bovino (Gibco ${ }^{\circledR}$-EUA) foi utilizado como soro controle negativo.

Complemento de cobaios (Laborclin ${ }^{\circledR}$ ) e hemolisina, anticorpo anti-hemácia de carneiro (Laborclin ${ }^{\circledR}$ ) foram utilizados na diluição correspondente a duas unidades hemolíticas. $\mathrm{O}$ sistema hemolítico, usado como sistema revelador do teste, foi preparado adicionando igual volume de hemolisina a uma solução de hemácias de carneiro, previamente diluídas a 2,0\% (v/v) em tampão veronal (CAMBREX ${ }^{\circledR}$ ).

A leitura foi realizada visualmente e os soros que apresentaram a formação de um botão de hemácias na diluição $\geq 32$ foram considerados sororreatores (OIE 2004).

\section{Análise estatística}

A propriedade foi considerada foco quando apresentou pelo menos um animal sororreator na prova de fixação de complemento. A estimativa da prevalência de focos foi feita pelo programa Epi Info 6.0.

As variáveis relacionadas no questionário epidemiológico para a identificação dos fatores de risco para Chlamydophila spp. foram: tipo de criação, tipo de exploração, raça predominante, número total de fêmeas existentes, presença de outras espécies de animais domésticos, presença de espécies silvestres de vida livre, uso de inseminação artificial, compra ou venda de machos ou fêmeas para reprodução, destino de fetos e placentas, aluguel de pasto, pastos comuns com outras propriedades, presença de áreas alagadiças na propriedade, presença de piquete para fêmeas na fase de parto e/ou pósparto e assistência veterinária. Cada uma das variáveis foi submetida ao teste de qui-quadrado e aquelas com valor de $p<0,20$ foram submetidas à regressão logística multivariada. Todas as análises foram realizadas com o auxílio do programa SPSS.

\section{RESULTADOS}

Dos 3.102 soros de fêmeas bovinas analisados, 44 $(1,42 \%)$ foram positivos para anticorpos anti-Chlamydophila spp., sendo que 41 deles apresentaram título de 32 e os outros três exibiram títulos de 64,128 e 256 . A prevalência de focos foi de $8,82 \%(6,15 \%-12,17 \%)$. Das 33 propriedades positivas, 25 apresentaram apenas um animal sororreator. A propriedade com maior número de animais positivos (4/9) estava localizada no município de Francisco Beltrão, região sudoeste do estado. As três propriedades amostradas nos municípios de Ivaiporã (norte pioneiro) e as três de Matelândia (região oeste) apresentaram pelo menos um animal positivo.

Os resultados da análise univariada constam do Quadro 1. O Quadro 2 apresenta o modelo final da regressão logística multivariada.
Quadro 1. Distribuição das variáveis analisadas como possíveis fatores de risco para Chlamydophila spp. em propriedades rurais, com histórico de abortamento, Paraná, 2007

\begin{tabular}{lccc}
\hline \multicolumn{1}{c}{ Variável } & $\begin{array}{c}\text { Expostos/ } \\
\text { casos }\end{array}$ & $\begin{array}{c}\text { Expostos/ } \\
\text { controles }\end{array}$ & $\begin{array}{c}\text { Valor } \\
\text { de p }\end{array}$ \\
\hline Rebanho confinado ou semi-confinado & $15 / 31$ & $97 / 341$ & $0,020^{*}$ \\
Exploração de leite & $17 / 32$ & $154 / 342$ & 0,461 \\
Predominância de raças puras & $12 / 31$ & $146 / 331$ & 0,562 \\
Rebanho com menos de 35 fêmeas & $26 / 32$ & $215 / 342$ & $0,038^{*}$ \\
Contato com ovinos & $2 / 32$ & $63 / 342$ & $0,082^{*}$ \\
Contato com eqüinos & $19 / 32$ & $240 / 342$ & 0,205 \\
Contato com suínos & $19 / 32$ & $241 / 342$ & $0,192^{*}$ \\
Contato com aves & $26 / 32$ & $307 / 342$ & $0,142^{*}$ \\
Contato com cão & $30 / 32$ & $314 / 342$ & 1,000 \\
Contato com gato & $23 / 32$ & $258 / 342$ & 0,656 \\
Contato com animais silvestres & $6 / 32$ & $103 / 342$ & $0,176^{*}$ \\
Utiliza a inseminação artificial & $3 / 31$ & $41 / 334$ & 0,895 \\
Compra de animais para reprodução & $18 / 32$ & $183 / 339$ & 0,806 \\
Venda de animais para reprodução & $8 / 32$ & $118 / 338$ & 0,258 \\
Deixa produtos do aborto na pastagem & $19 / 30$ & $151 / 331$ & $0,131^{*}$ \\
Aluga pasto & $10 / 32$ & $61 / 340$ & $0,067^{*}$ \\
Pasto comum com outras propriedades & $4 / 32$ & $57 / 341$ & 0,538 \\
Presença de áreas alagadiças & $8 / 32$ & $81 / 336$ & 0,910 \\
Presença de piquetes de parição & $10 / 32$ & $117 / 337$ & 0,693 \\
Ausência de assistência veterinária & $21 / 31$ & $206 / 335$ & 0,493
\end{tabular}

* Variável oferecida à regressão logística multivariada $(p<0,20)$.

Quadro 2. Fatores de risco para Chlamydophila spp em propriedades rurais com histórico de abortamento, Paraná, 2007

\begin{tabular}{lccc}
\hline Variáveis & OR & $95 \%$ IC & Valor p \\
\hline Rebanho confinado ou semi-confinado & 3,339 & {$[1,477-7,552]$} & 0,004 \\
Rebanho com menos de 35 fêmeas & 3,339 & {$[1,246-8,953]$} & 0,017 \\
Deixa produtos de aborto na pastagem & 2,372 & {$[1,052-5,348]$} & 0,037 \\
Aluga pasto & 3,398 & {$[1,411-8,182]$} & 0,006
\end{tabular}

\section{DISCUSSÃO}

Em bovinos, o desenvolvimento da resposta imunológica ocorre principalmente após o abortamento, persistindo por vários meses e depois, com a cronicidade da doença os títulos tendem a cair (Wilsmore et al. 1984, Schmeer et al. 1987). Nesse estudo, o critério de inclusão foi propriedade com histórico de aborto nos últimos 12 meses. Assim, os baixos títulos aqui observados podem ter sido decorrentes do declínio dos anticorpos em conseqüência da cronicidade da doença ou pela não ocorrência de aborto nos animais estudados, uma vez que o histórico de abortamento era da propriedade e não dos animais. Predominância de títulos baixos (32) já foi descrita na Itália, Polônia e Alemanha (Cavirani et al. 2001, Niemczuk 2005, Wehrend et al. 2005).

A prevalência de focos encontrada para o estado do Paraná foi de $8,82 \%$ (33/373), muito inferior à observada por Igayara-Souza et al. (2004) no estado de São Paulo, onde $51,9 \%$ (14/27) das propriedades avaliadas apresentaram animais com anticorpos contra Chlamydophila. Isso pode ser conseqüência das diferenças metodológicas entre os dois estudos, como critério de seleção e tamanho da amostragem. Igayara-Souza et al. (2004) examinaram ape- 
nas 27 propriedades, 14 de exploração leiteira e 13 de corte, pertencentes à apenas duas regiões do estado de São Paulo, oeste e sudoeste. Destas propriedades, apenas 11 não relatavam histórico de aborto recente, entretanto este período de tempo considerado recente não foi detalhado.

De maneira análoga, a freqüência de animais sororreatores $(1,42 \%, 44 / 3.102)$ no estado do Paraná também foi inferior àquela verificada por Igayara-Souza et al. (2004) no estado de São Paulo (5,3\%). Na Europa, foram relatadas prevalências variando de $2 \%$ a $45 \%$ (Cavirani et al. 2001, Niemczuk 2005, Wehrend et al. 2005).

Portanto, a baixa prevalência de focos e de animais, associada à forte evidência de baixa prevalência intra-rebanho (25 das 33 propriedades foco apresentaram apenas um animal reator) em propriedades com histórico de aborto, sugere que a infecção por Chlamydophila spp. no Estado do Paraná não parece ser causa de abortamento das mais relevantes.

O modelo final de regressão logística apontou quatro variáveis associadas à condição de foco de Chlamydophila spp.: propriedade com menos de 35 fêmeas, rebanho confinado ou semi-confinado, produtos de abortamento na pastagem e aluguel de pasto.

O fato da condição de foco estar associada a propriedades com até 35 animais não tem nenhum significado do ponto de vista de recomendações visando a prevenção. O número de animais da propriedade freqüentemente aparece nos modelos finais de regressão logística, para as mais variadas doenças, porém é uma variável destituída de valor prático, mostrando apenas que a infecção está associada a determinado tamanho de propriedade.

A aglomeração de animais, através do confinamento ou do semi-confinamento, amplia as possibilidades de manutenção e difusão da infecção dentro do rebanho, pois aumenta a taxa de contato entre os animais (Mainar-Jaime et al. 1998, DeGraves et al. 2004).

Após aborto ou parto, grande número de corpos elementares, forma infectante de Chlamydophila spp., é eliminado com os líquidos placentários e envoltórios fetais, contaminando o meio ambiente. A ingestão destes corpos elementares, principal modo de transmissão do microrgansimo para outros animais, deve ser evitada, sendo necessário a correta destinação destes produtos de aborto ou parto para a prevenção da infecção (Longbottom \& Coulter 2003, Kaltenboeck et al. 2005).

$\mathrm{O}$ aluguel de pasto pode favorecer a transmissão de Chlamydophila spp., além de outros microrganismos patogênicos, pois significa contato com outra propriedade pela inclusão de animais com condição sanitária desconhecida no rebanho. Estes animais oriundos de outras propriedades podem atuar como possíveis fontes de infecção para Chlamydophila spp.

\section{CONCLUSÕES}

Os resultados indicam que a infecção de bovinos por Chlamydophila spp. ocorre no estado do Paraná, porém acomete um número pequeno de propriedades com his- tórico de aborto e um número pequeno de animais. Assim, a importância do agente como causa de aborto em bovinos neste Estado, se existir, é muito pequena.

Com vistas à prevenção, deve-se evitar aglomeração de animais, o contato indireto entre propriedades através de aluguel de pasto e deve-se incentivar a remoção de restos de abortos das pastagens seguida da destinação adequada.

\section{REFERÊNCIAS}

Buendía A.J., Cuello F., Del Rio L., Gallego M.C., Caro M.R. \& Salinas J. 2001. Field evaluation of a new commercially avaiable ELISA based on a recombinant antigen for diagnosing Chlamydophila abortus (Chlamydia psittaci serotype 1) infection. Vet. Microbiol. 78:229-239.

Cavirani S., Cabassi C.S., Donofrio G., De laco B., Taddei S. \& Flammini C.F. 2001. Association between Chlamydia psittaci seropositivity and abortion in Italian dairy cows. Prev. Vet. Med. 50:145-151.

Corsaro D., Valassina M. \& Venditti D. 2003. Increasing diversity within Chlamydiae. Critical Rev. Microbiol. 29(1):37-78.

Dean A.G., Dean J.A., Coulombier D., Brendel K.A., Smith D.C., Burton A.H., Dicker R.C., Sullivan K., Fagan R.F. \& Arner T.G. 1994. Epi Info, Version 6: a word processing, data base and statistics program for epidemiology on microcomputers. Centers for Disease Control and Prevention, Atlanta, Georgia, USA.

DeGraves F.J., Kim T., Jee J., Schlapp T., Hehnen H.R. \& Kaltenboeck B. 2004. Reinfection with Chlamydophila abortus by uterine and indirect cohort routes reduces fertility in cattle preexposed to Chlamydophila. Infect. Immun. 72(5):2538-2545.

Dias J.A. 2003. Soroepidemiologia da brucelose bovina e bubalina no estado do Paraná. Dissertação de Mestrado em Ciência Animal, Área de Concentração Sanidade Animal, Universidade Estadual de Londrina, Paraná. 48p.

Donn A., Jones G.E., Ruiu A., Ladu M., Machell J. \& Stancanelli A. 1997a. Serological diagnosis of chlamydial abortion in sheep and goats: comparison of the complement fixation test and an enzyme-linked immunosorbent assay employing solubilised proteins as antigen. Vet. Microbiol. 59:27-36.

Donn A., Carnieletto P., Chiaracane G., Ladu M., Matchell J., Mandola M.L., Ruiu A., Stancanelli A. \& Turilli C. 1997b. Standardizzazione della tecnica di fissazione del complemento per la dimostrazione di anti-chlamydia nel siero de sangue. Progresso Veterinário 4:125-128.

Everett K.D.E. 2000. Chlamydia and Chlamydiales: more than meet the eye. Vet. Microbiol. 75:109-126.

Griffiths P.C., Plater J.M., Martin T.C., Hughes S.L., Hughes K.J., Hewinson R.G. \& Dawson M. 1995. Epizootic abortion in a herd: Characterization of a Chlamydia psittaci isolate and antibody response. Brit. Vet. J. 151(6):683-693.

Hässig M. \& Lubsen J. 1998. Relationship between abortions and seroprevalences to selected infectious agents in dairy cows. J. Vet. Med. B 45:435-441.

Igayara-Souza C.A., Genovez M.E., Ferreira F., Paulin L.M., Scarcelli E., Cardoso M.V. \& Turilli C. 2004. Ocorrência de anticorpos antiChlamydophila em bovinos e sua relação com distúrbios reprodutivos. Revta Bras. Reprod. Anim. 28(1):28-33.

Kaltenboeck B., Hehnen H.R. \& Vaglenove A. 2005. Bovine Chlamyophila spp infection: Do we underestimate the impact on fertility? Vet. Res. Commun. 29(Suppl.1):1-15.

Lima B.A.C. 2007. Prevalência de anticorpos contra Chlamydophila spp. em ovinos de propriedades localizadas na região de Londrina, Paraná. Dissertação de Mestrado em Ciência Animal, Área de Concentração Sanidade Animal, Universidade Estadual de Londrina, Paraná. $55 p$. 
Longbottom D. \& Coulter L.J. 2003. Animal chlamidiosis and zoonoic implication. J. Comp. Pathol. 128:217-244.

Mainar-Jaime R.C., de la Cruz C. \& Vázquez-Boland J.A. 1998. Epidemiologic study of chlamydial infection in sheep farms in Madrid, Spain. Small Ruminant Research 28:131-138.

Niemczuk K. 2005. Prevalence of antibodies against Chlamydophila psittaci and Chlamydophila abortus in cattle in Poland. A preliminary report. Bull. Vet. Inst. Pulawy 49:293-297.

OIE 2004. Ovine chlamydiosis. In: Manual of Standards for Diagnostic Tests and Vaccines. $5^{\text {th }}$ ed. World Organization for Animal Health, Paris. Acessado em 2.10.2006. Online. Disponível em: http:// www.oie.int/eng/normes/mmanual/A_00073.htm.

Otte M.J., Ravenborg T. \& Hüttner K. 1995. A pilot study of elevated abortion and stillbirth ratios in cattle in the foothills of the Eastern plains of Colombia. Prev. Vet. Med. 22:103-113.
Schachter J. \& Caldwell H.D. 1980. Chlamydiae. Annu. Rev. Microbiol. 34:285-309.

Schmeer N., Schnorr K.L., Perez-Martinez J.A. \& Storz J. 1987. Dominance of Chlamydophila psittaci-specific IgG2 subclass in the humoral responses of naturally and experimentally infected cattle. Vet. Immunol. Immunopathol. 15:311-322.

Stamp J.T., Watt J.A.A. \& Cockburn R.B. 1952. Enzootic abortion in ewes: Complement fixation test. J. Comp. Pathol. 62:93-101.

Twomey D.F., Griffiths P.C., Horigan M.W., Hignett B.C. \& Martin T.P. 2006. An investigation into the role of Chlamydophila spp. in bovine upper respiratory tract disease. Vet. J. 171:574-576.

Wehrend A., Failing K., Hauser B., Jäger C. \& Bostedt H. 2005. Production, reproductive, and, metabolic factors associated with chlamydial seropositivity and reproductive tract antigens in dairy herds with fertility disorders. Theriogenology 63:923-930. 